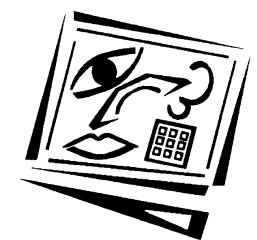

\title{
The iPortfolio: Measuring uptake and effective use of an institutional electronic portfolio in higher education
}

\author{
Brian R. von Konsky and Beverley Oliver \\ Curtin University
}

\begin{abstract}
An institutional electronic portfolio called the iPortfolio had over 17,000 subscribers one year after its introduction at an Australian university. This paper reports on a study to determine how students use these iPortfolio accounts, and factors leading to uptake and effective use. Self-assessed competence with technology skills, factors motivating uptake, and barriers to adoption were examined using an online survey completed by 554 students. Of these, 339 had an iPortfolio at the time they completed the survey. Survey results were examined in the context of usage patterns based on data automatically collected for operational and administrative purposes. No statistically significant difference in prior technology use or self-assessed competence with information technology was observed when comparing students with iPortfolio accounts to those without. Assessment was found to be the principal driver of iPortfolio uptake. However, about two-fifths (42.9\%) of students agreed that they were likely to use the iPortfolio in the future, even if it was not a course requirement. An additional $29.6 \%$ were neutral. Significant use of the iPortfolio to reflect on extracurricular activities was not observed. Improved employability outcomes were seen to be a benefit of iPortfolio adoption by about half $(52 \%)$ of the students. Recommendations are made to promote iPortfolio uptake and encourage student reflection on 'lifewide' experiences that enhance employability and augment learning within the formal curriculum.
\end{abstract}

\section{Introduction}

A focus on graduate employability is part of the 'moral purpose' of universities, with a majority of students enrolling in a course of study to begin or advance a career. In the University and Beyond 2007 survey that elicited responses from some 32,000 Australian university students, approximately half the respondents, mostly undergraduates, agreed that they enrolled in their course because they had a particular career in mind. A further 19\% enrolled because they thought their current course would improve their employment prospects (Graduate Careers Australia, 2008). Nevertheless, the 2009 Australian Universities Survey of Student Engagement (AUSSE) found that more than half of the 35,000 undergraduate respondents had never talked about their career plans with teaching staff and felt ill-equipped to enter the workforce. More than a third would leave university without an up to date resume (Australian Council for Educational Research, 2010).

In this setting, many Australian universities have begun using or are investigating the adoption of program and institution-wide electronic portfolio systems (Hallam, Harper, et al., 2008). Electronic portfolios, also called ePortfolios or e-portfolios, have become increasingly popular in recent years as a vehicle for the collection of learning 
artefacts, and for reflection on those artefacts, in order to develop graduate attributes and employability skills (Knight \& Yorke, 2006). Sutherland and Powell define an eportfolio as "a purposeful aggregation of digital items - ideas, evidence, reflections, feedback - which 'presents' a selected audience with evidence of a person's learning and/or ability" (Sutherland \& Powell, 2007). Increasingly, many recognise that eportfolios have potential benefits for both graduates and employers. In part, this is because employers are able to obtain a more informed picture of a candidate than is usually provided by a traditional curriculum vitae (Business Industry and Higher Education Collaboration Council, 2007). The e-portfolio has been recognised as both a tool and a process that can help students trace their learning journey by providing the opportunity to demonstrate and reflect on learning outcomes to enhance the educational experience (Hallam \& McAllister, 2007).

The ALTC-funded Australian ePortfolio Project (AeP) found a high level of interest in the use of e-portfolios in the higher education sector. Responses to the national audit of e-portfolio activity indicated a high level of interest in e-portfolios as a means of enhancing the student experience through meaningful engagement with the educational experience (Hallam, Harper, McAllister, Hauville \& Creagh, 2010; Hallam, Harper, et al., 2008). Student feedback on e-portfolio experiences indicates that students value the opportunity to focus on personal and professional strengths and weaknesses and to explicitly align learning and the workplace. Feedback indicated that students would appreciate e-portfolio technology that draws together a range of applications, such as informal social networking software into formal educational eportfolio activity (Hallam, Harper, et al., 2008).

Students are increasingly likely to possess devices for accessing online learning systems as well as the online tools typically associated with e-portfolio systems (Oliver \& Nikoletatos, 2009; Oliver \& Whelan, 2011). For example, current students are sharing online digital media and engaging with others using Web 2.0 technologies for social networking purposes (ABC Television, 2008; Kvavik, Caruso \& Morgan, 2004; Caruso \& Kvavik, 2005; Salaway \& Caruso, 2007; Rosenbloom, 2007). Similarly, it is now commonplace for higher education institutions to use a learning management system (LMS) to support the online, blended, and face to face delivery of academic programs (Coates, 2005). An LMS offers students access to a wide range of resources and activities with the potential to foster engaging and collaborative online learning experiences. This can make content more cognitively accessible through interaction with learning material, peers, and learning facilitators while simultaneously developing technology literacy skills.

Logged data directly available from the LMS and institutional web servers have been increasingly referred to as learning analytics (Elias, 2011; Hrabowski, Suess \& Fritz, 2011; Johnson, Smith, Willis, Levine \& Haywood, 2011). The data are analysed to map usage patterns associated with accessing online resources, participation in online learning experiences, and learning outcomes. For example, video streaming logs have been used to measure the impact of lecture recordings made available online on lecture attendance and final marks (von Konsky, Ivins \& Gribble, 2009). Similarly, server logs have been analysed by Pennsylvania State University to investigate when students access course materials relative to assignment deadlines; the results informed the design of subsequent assessments (Mathews, Haughton, Pisupati, Scaroni \& DiBase, 2004). Mazzolini and Maddison (2003) accessed logs from online discussion boards to determine how the rate and style of moderator posts impact the rate at which students post, and on student evaluation of their learning experiences. 
Others have studied factors that lead to the uptake of educational technologies, and barriers to adoption. For example, a survey influenced by Rogers' (2003) Diffusion of Innovation theory was used to identify factors that influence the uptake of teaching blogs by secondary school teachers (Lai \& Chen, 2011). That study found that the most significant factor impacting teaching blog uptake was teacher perceptions of the time and effort required to do so. In a similar study, Swan (2009) found that academic staff valued the introduction of electronic portfolios over paper-based alternatives when evaluating student artifacts, particularly with respect to large student cohorts. In particular, Swan's work reported that many academics valued the data management benefits of using an e-portfolio over a paper-based approach. However, Swan also reported that some academics preferred giving students informal verbal feedback over written feedback via the e-portfolio system.

Similarly, studies have been undertaken to investigate student perceptions regarding the benefit of e-portfolio systems. For example, Lopez-Fernandez and Rodriguez-Illera (2009) had students complete a preliminary survey, monthly questionnaires, and a final reflection regarding their e-portfolio experience in an undergraduate subject. Overall, students reported that using an e-portfolio was a positive experience. However, some were skeptical that use of the e-portfolio had a significant impact on their learning. Shroff, Deneen and Ng (2011) have shown that student attitudes toward e-portfolio use are impacted by perceptions regarding ease of use and usefulness. Similarly, Tzeng (2011) investigated the perceived value that students place on eportfolio use from epistemic, functional, and contextual perspectives. This work reported that initial functional perceptions are important factors which influence the overall value that students place on e-portfolios, together with the level of promotion, support, and documentation provided in an institutional context.

However, little work has been reported to relate actual e-portfolio usage patterns to student perceptions, particularly in the context of lifewide experiences that support formal coursework and the development of employability skills. The present paper fills this gap, reporting on usage patterns and student perceptions of an institutional eportfolio called the iPortfolio, developed and deployed at Curtin University in Perth, Australia.

\section{The iPortfolio}

Following broad consultation with staff and student, the iPortfolio was implemented with the goals of enhancing employability and engagement with learning (Oliver, von Konsky, Jones, Ferns \& Tucker, 2009; von Konsky, Oliver \& Ramdin, 2009). The iPortfolio is an online space where students collect and reflect on artefacts related to their learning and professional development, seek feedback from peers, mentors and learning facilitators, and showcase finished examples of their skills and abilities. Students can use their iPortfolio indefinitely after graduation to facilitate their lifelong learning and professional development. This is possible because the iPortfolio is not dependent on fixed infrastructure using local servers. Instead, the iPortfolio uses an architecture that is based on a cloud solution. This approach shifts costs from capital to operational expenditures, resulting in an electronic portfolio system that is both scalable and sustainable. Additionally, the iPortfolio was designed to support lifewide learning that complements the formal curriculum. It provides features that facilitate reflection on whole-of-life experiences that support the learner's on-going professional 
development. These include experiences that arise as a result of paid employment, extracurricular activities, student clubs, and community service.

The iPortfolio is not based on an existing social networking web site or commercial product. It is a bespoke system built in-house. A fundamental design principle is its focus on the University's philosophy of teaching and learning, articulated as the attainment of Curtin's graduate attributes and the triple-i curriculum. The triple-i curriculum highlights industry readiness; inclusivity (indigenous, intercultural, and international competence); and an interdisciplinary focus (Oliver, von Konsky, Jones, Ferns \& Tucker, 2009). The iPortfolio enables students to create, collect and curate evidence of achievement of these outcomes by uploading learning artefacts in formats that include images, movies, audio, Portable Document Format (PDF) and various Microsoft Office document types. Students can tag uploaded evidence as representative of one or more of the graduate attributes and triple-i experiences before being incorporated with critical reflections in entries under a set of predefined tab headings:

About $\mathrm{Me}$ - a profile picture, introductory and biographical information and a statement of goals;

My Ratings - self-assessed progress towards attainment of the graduate attributes and triple-i curriculum;

My Course - course work and the attainment of professional competencies;

My Employment - paid employment, outside jobs, work placements, and resumes;

My Journals - reflective journals, including those used for site visits and work experience;

My Networks - organisations and individuals impacting learning and professional development; and

My Showcases - finished work highlighting special skills and abilities.

The iPortfolio includes course and unit specific templates to guide student reflection on learning and professional competencies, and social networking features to invite individuals and collaborative groups to offer their feedback.

The About Me tab in an example iPortfolio is shown in Figure 1. The Evidence Manager, used to upload, tag, and organise evidence, can be seen on the right hand side of the figure. The social networking area used to invite others to view or provide feedback on the About Me entry can be seen in the lower left hand corner.

The iPortfolio system was piloted in the latter half of 2009, during which feedback was collected on a range of usability issues from 2000 staff and students. During the pilot, an additional 2871 accounts were created for staff and students not formally participating in the pilot, and for scholars external to the University. In total 4871 accounts were created during the pilot period. The iPortfolio was refined based on pilot feedback. Beginning in February 2010, the iPortfolio was introduced to the whole of the University community, consisting of approximately 41,000 students, nearly 17,000 of whom were offshore and onshore international students. Over 17,000 iPortfolio accounts had been created by December 2010, less than one year after its initial introduction. New accounts were created at a relatively consistent rate over the whole of this period, as shown in Figure 2. The creation of new accounts peaked at the beginning of each semester, as shown in Figure 3. 


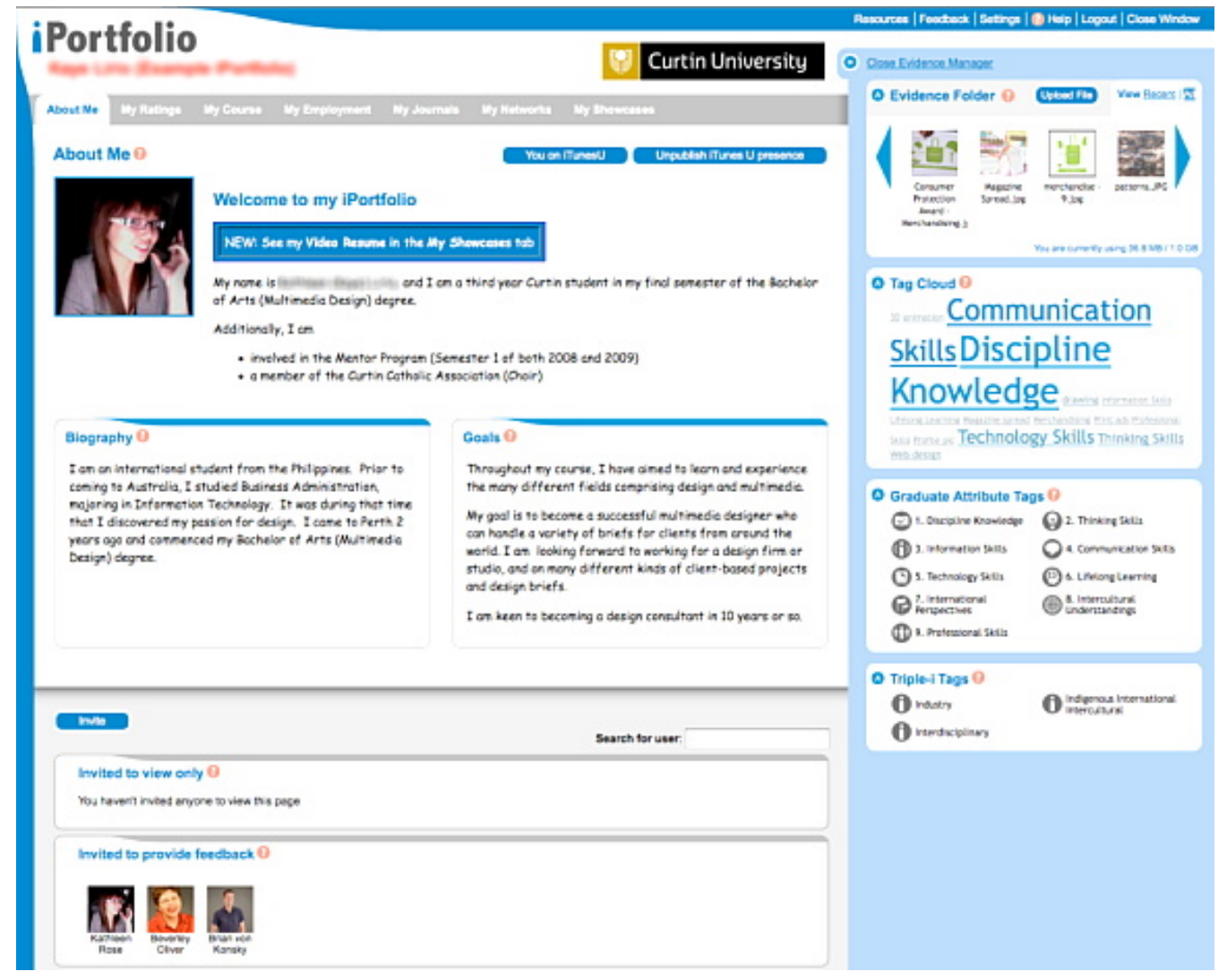

Figure 1: The iPortfolio tabs (upper left), Evidence Manager (right) and feedback area (lower left).

However, how students were actually using these accounts was not known. While the iPortfolio had been woven into the assessment pattern of some units, how other students were actually using their iPortfolio accounts was not well understood, particularly in an extracurricular context. This paper describes a study investigating factors influencing the uptake and use of the iPortfolio. The study uses results from a student survey in conjunction with usage data routinely collected for administrative and operational purposes.

The investigation was intended to address the following research questions:

Research Question 1:

What factors influenced iPortfolio uptake and use in this early implementation phase? Research Question 2:

How did students use the iPortfolio: which features did they use and why? Which media formats were uploaded and how were they tagged?

Research Question 3:

To what extent did self-assessed technology competence and prior experience with information technology impact iPortfolio uptake and use? 
The goal of the research was to develop a set of recommendations to enhance the uptake and effective use of the iPortfolio based on objective data, in order to improve learning and employability.

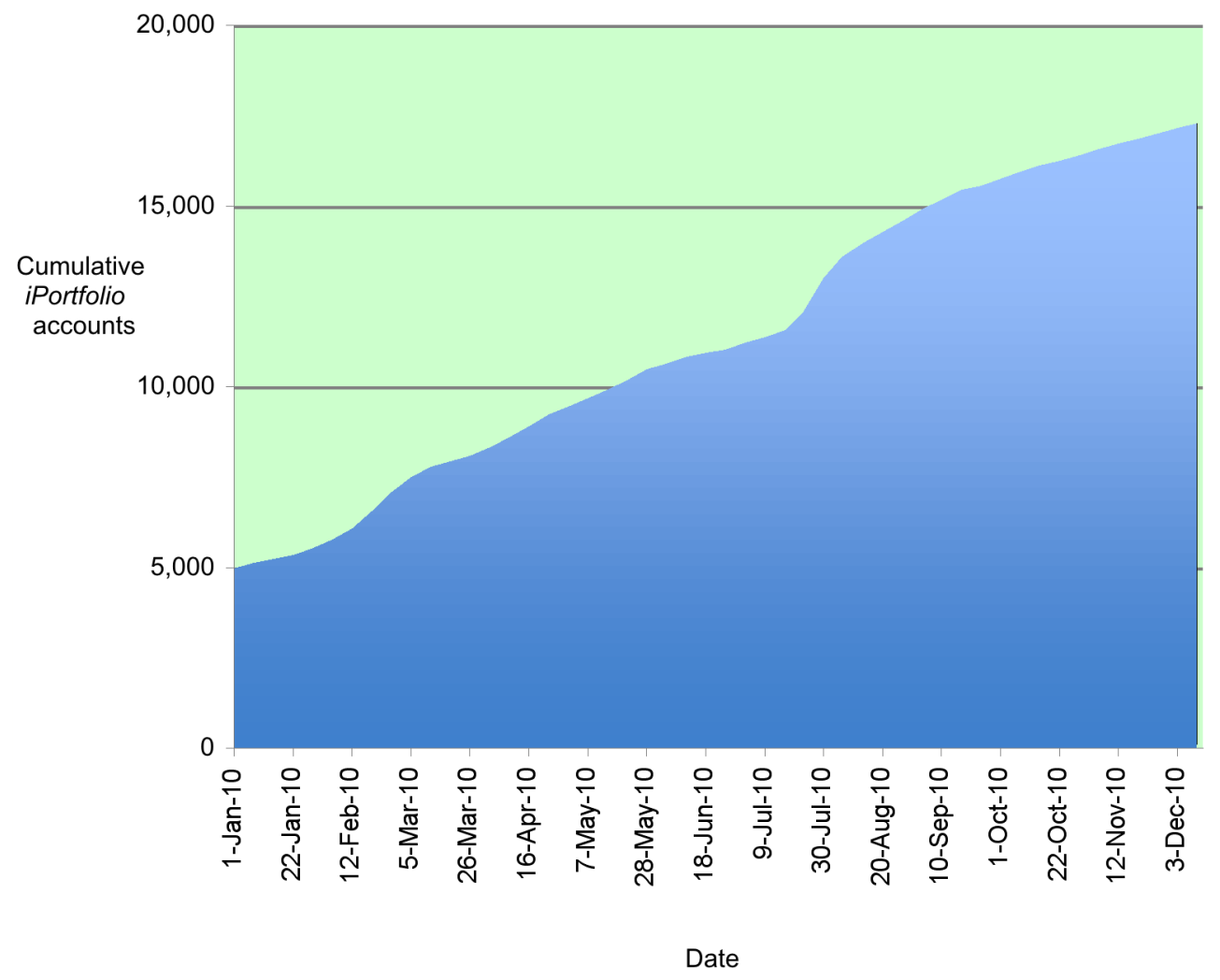

Figure 2: Cumulative iPortfolio uptake

\section{Method}

A mixed-mode study was adopted, utilising automatically recorded data from the iPortfolio server in addition to the results of an online student survey. Unlike prior studies based solely on student perceptions and self-report usage data (LopezFernandez \& Rodriquez-Illera, 2009; Shroff, et al., 2011; Tzeng, 2011), the present study examined survey results in the context of actual usage data automatically recorded on the iPortfolio server.

The online survey was administered through the University student portal over a fourweek period beginning in late 2010. The survey items related to:

Demographics and prior experience

Age group, faculty affiliation, first language, prior experience with information technology, and prior experience with portfolios (electronic or paper).

Generic skills

Perceptions of personal competence in technical, communication, and lifelong learning skills that could impact iPortfolio uptake and the user experience. 
iPortfolio benefits

Perceptions of iPortfolio compatibility with existing values and practices and its contribution to learning and employability. Those with iPortfolio accounts at the time of the survey were also asked their opinions regarding iPortfolio usability and ease of use.

iPortfolio use

Intentions regarding future $i$ Portfolio use, and the factors that would motivate or hinder this. Prior use of the iPortfolio by those with accounts at the time of the survey was also queried. Questions included the extent to which the iPortfolio was used for coursework, fieldwork, and extra-curricular activities.

Open-ended comments

Feedback on how the iPortfolio might be improved.

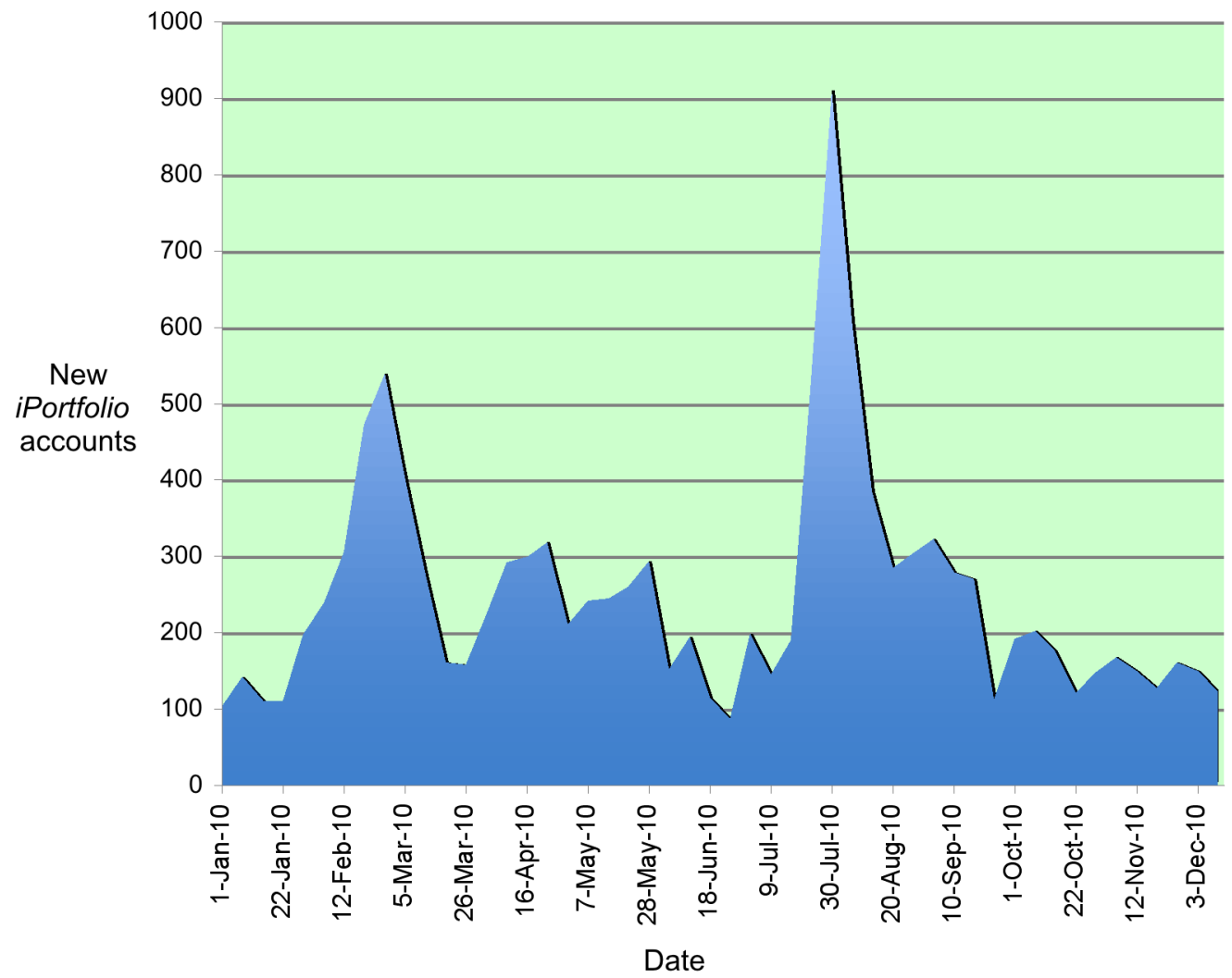

Figure 3: iPortfolio uptake per week

For those with iPortfolio accounts, survey results were anonymously keyed and compared with usage data automatically collected by the iPortfolio system. These data included:

Date of the last tab modification and the number of updates

This facilitated determining how many of those with iPortfolio accounts used them actively, and which of the available tabs students tended to use.

Media format asset count 
These data capture the number of assets uploaded (images, movies, audio, document files in various formats, and PowerPoint slides). This facilitated determining if students used media rich formats, particularly important when showcasing skills that are difficult to demonstrate in paper-based formats.

Tag counts

This facilitated determining the extent to which students tagged artefacts with the graduate attributes, triple-i curriculum, and custom tags.

Participation in the study was voluntary. Two randomly-drawn cash prizes were used as an incentive to encourage student participation. When students followed the link to the online survey, they were presented with a brief information sheet giving details about the study. Students provided their consent to participate by completing the survey. This study was approved in accordance with the Human Research Ethics process prescribed by Curtin University (Approval Number RD-40-10).

\section{Results}

A total of 554 students participated in the study. Of these, 339 had iPortfolio accounts, but 2 were subsequently excluded due to incomplete demographic information. Of the remaining 337 participants, usage data shows that just less than half (156 or 46.3\%) had not modified entries under any tab and were therefore classified as inactive users. That is, just over half (53.7\%) of those with iPortfolio accounts were classified as active users, and $46.3 \%$ had created an iPortfolio account but had generally not used it. Of the inactive users, $10.3 \%(\mathrm{~N}=16)$ had uploaded assets. To some extent, this corroborated anecdotal evidence that some students did not understand that it was necessary to upload items into the iPortfolio Evidence Manager and then insert these into new $i$ Portfolio entries within the tabs.

A total of $50.8 \%(\mathrm{~N}=92)$ of the 181 active accounts came from Health Sciences, 23.2\% $(\mathrm{N}=42)$ came from Business, $21 \%(\mathrm{~N}=38)$ came from Science and Engineering, and 5\% $(\mathrm{N}=9)$ came from Humanities. This distribution is generally consistent with the extent to which the iPortfolio has been woven into the assessment pattern of units and courses, and suggests that assessment is the principal driver of $i$ Portfolio uptake.

Of the 181 students who had modified iPortfolio entries, 3.9\% ( $\mathrm{N}=7)$ last did so during the 2009 pilot study, 38.1\% ( $\mathrm{N}=69)$ last modified their iPortfolio in the first half of 2010, and $58 \%(\mathrm{~N}=108)$ last modified their iPortfolio in the last half of 2010.

There was no statistically significant difference between those with an iPortfolio account and those without, with respect to gender (Chi-squared=1.091, d.f. $=1, p>0.5$ ), age group (Chi-squared=1.847, d.f. $=3, \mathrm{p}>0.5$ ), level of study (Chi-squared=1.761, d.f. $=2, p>0.5$ ) or language group (Chi-squared $=0.531$, d.f. $=4, p>0.5$ ). Those with and without accounts were somewhat similar with respect to campus location (Chisquared $=11.925$, d.f. $=5, p>0.01$ ). However, there was a statistically significant difference between those with and without accounts with respect to faculty affiliation (Chi-squared $=36.668$, d.f. $=4, p<0.5$ ). In part, this difference in distribution can be attributed to the Faculty of Health Sciences utilising the iPortfolio more heavily for assessment purposes compared to other faculties. For example, the Faculty of Health Sciences constituted just over half (50.8\%) of the active iPortfolio accounts in the study. In contrast, use of the iPortfolio was largely voluntary in the Faculty of Humanities, where iPortfolio uptake was smaller and constituted only $5 \%$ of the active accounts. A 
further breakdown by faculty showing the number of active and inactive iPortfolio accounts is given in Table 1 .

Table 1: Number participants by faculty and level of iPortfolio use

\begin{tabular}{|l|c|c|c|c|}
\multirow{2}{*}{ Faculty } & \multirow{2}{*}{ No iPortfolio } & \multicolumn{2}{c}{ iPortfolio account owners } & \multirow{2}{*}{ Total } \\
\cline { 3 - 4 } & & Active & Inactive & \\
\hline Business & 81 & 42 & 53 & 176 \\
\hline Health Science & 66 & 92 & 34 & 192 \\
\hline Humanities & 41 & 9 & 17 & 67 \\
\hline Science and Engineering & 25 & 38 & 52 & 115 \\
\hline Other & 2 & 0 & 0 & 2 \\
\hline Total & 215 & 181 & 156 & 552 \\
\hline
\end{tabular}

\section{Prior portfolio use and experience with information technology}

Many students reported having prior portfolio experience: almost half $(46.6 \%)$ of respondents reported keeping a paper-based portfolio, and almost a quarter $(23.9 \%)$ reported keeping an electronic portfolio other than the iPortfolio. However, it is likely that there was a wide range in how survey questions related to prior use were interpreted. Keeping a paper-based portfolio could be interpreted to mean that examples of prior work including assignments and certificates are kept in a folder in printed form. Prior use of an electronic portfolio could mean that the student kept a portfolio in an online format. Alternatively, a positive response to this question could simply mean that the student kept an electronic archive of prior work on a home computer. It was also not clear if students defined the term portfolio to mean an archive of prior work alone, or if this also included critical reflections on the learning.

Most students had previous experience using at least one social networking site. This included Facebook (89.7\%), Twitter (14.5\%), My Space (7.8\%), and LinkedIn (6.7\%). However, those with iPortfolio accounts had a statistically significant higher tendency to spend slightly more time on social networking sites that those without (Chisquared $=45.168$, d.f. $=3, p<0.5$ ). There was no statistically significant difference in the frequency with which they checked email (Chi-squared $=3.387$, d.f. $=3, p>0.5$ ), played online multi-user games or accessed virtual worlds (Chi-squared $=2.184$, d.f. $=4$, $p>0.5$ ). A majority of respondents reported that they checked email on a daily basis (71.4\%) and never played online multi-user games or accessed virtual worlds $(68.3 \%)$.

\section{The iPortfolio and generic capabilities}

Of those without iPortfolio accounts, about a third (35.4\%) had not heard about the iPortfolio, and about half $(54 \%)$ did not know peers who had used it. About a third (34.9\%) indicated that they intended to use the iPortfolio, but had not yet done so. Just less than a third $(29.8 \%)$ of those without accounts were neutral and did not indicate if they were likely to use the iPortfolio in the future or not. A breakdown of responses is given in Figure 4.

Those who had active iPortfolio accounts, however, were generally positive about the benefits. A breakdown of their opinions of the relative benefit of using the iPortfolio is given in Figure 5. 


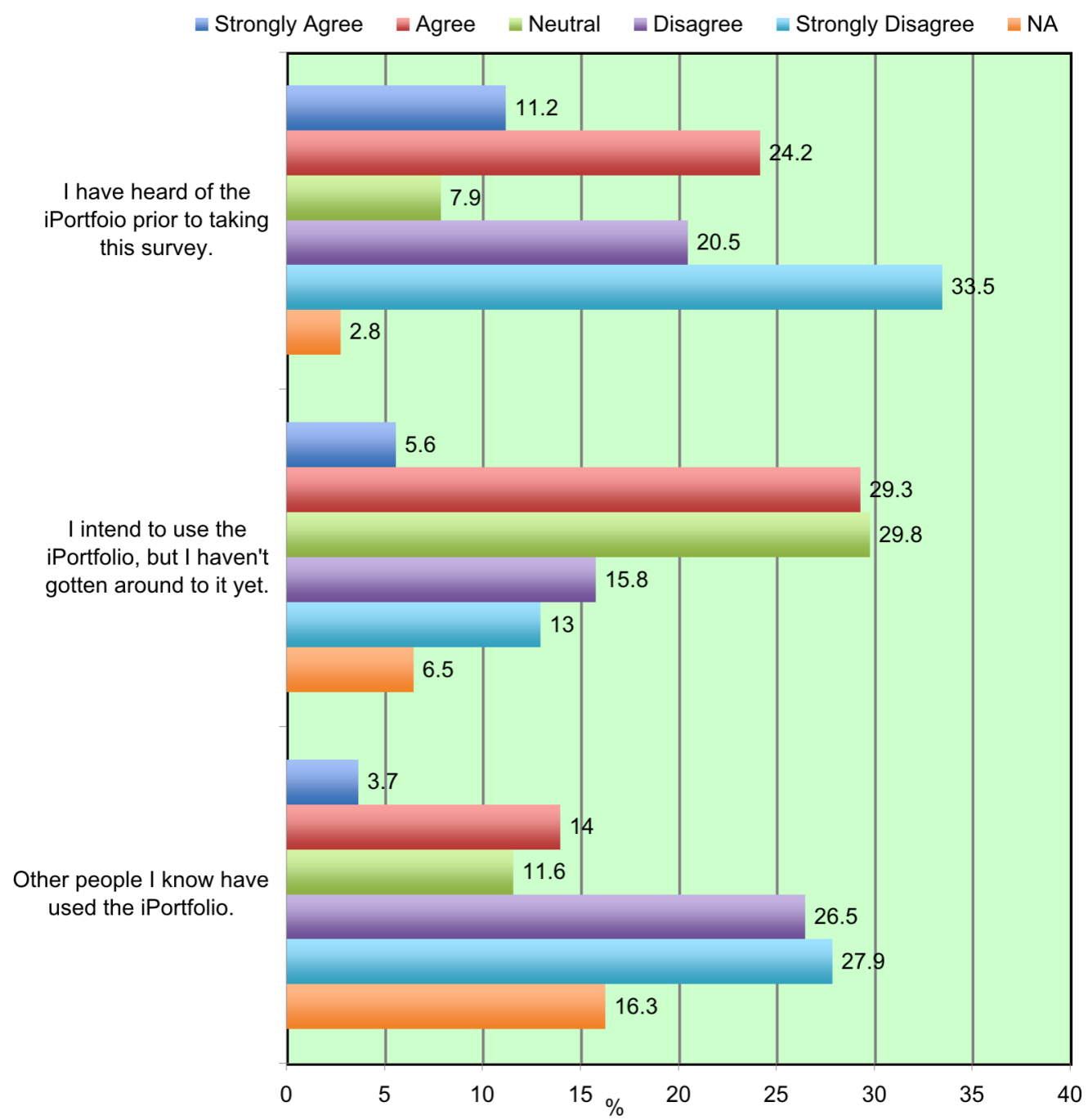

Figure 4: Prior exposure and intention of those without iPortfolio accounts.

In particular, just over half (59\%) reported that the iPortfolio provided a better way to showcase skills and abilities to others. Similarly, just over half $(54 \%)$ indicated that the $i$ Portfolio improved their ability to see progress in their course. Similarly, $44 \%$ reported that learning experiences associated with the iPortfolio assisted their learning, and $43 \%$ indicated that the iPortfolio had assisted them to identify strengths and areas for improvement. There were $42 \%$ with the view that the iPortfolio provides an advantage in the job market.

Few active account holders indicated that the iPortfolio did not provide benefits with respect to the learning and employability: $16 \%$ indicated that the iPortfolio did not improve their ability to assess progress in their course, and 18\% reported that learning experiences requiring iPortfolio use did not help them to learn. Although those with 
active accounts were generally positive about the benefits of the iPortfolio, a substantial number neither agreed nor disagreed with statements about iPortfolio benefits. For example, 33\% were neutral with respect to the iPortfolio providing an advantage in the job market, and $29 \%$ were neutral about the iPortfolio providing a better means to seek feedback on learning.

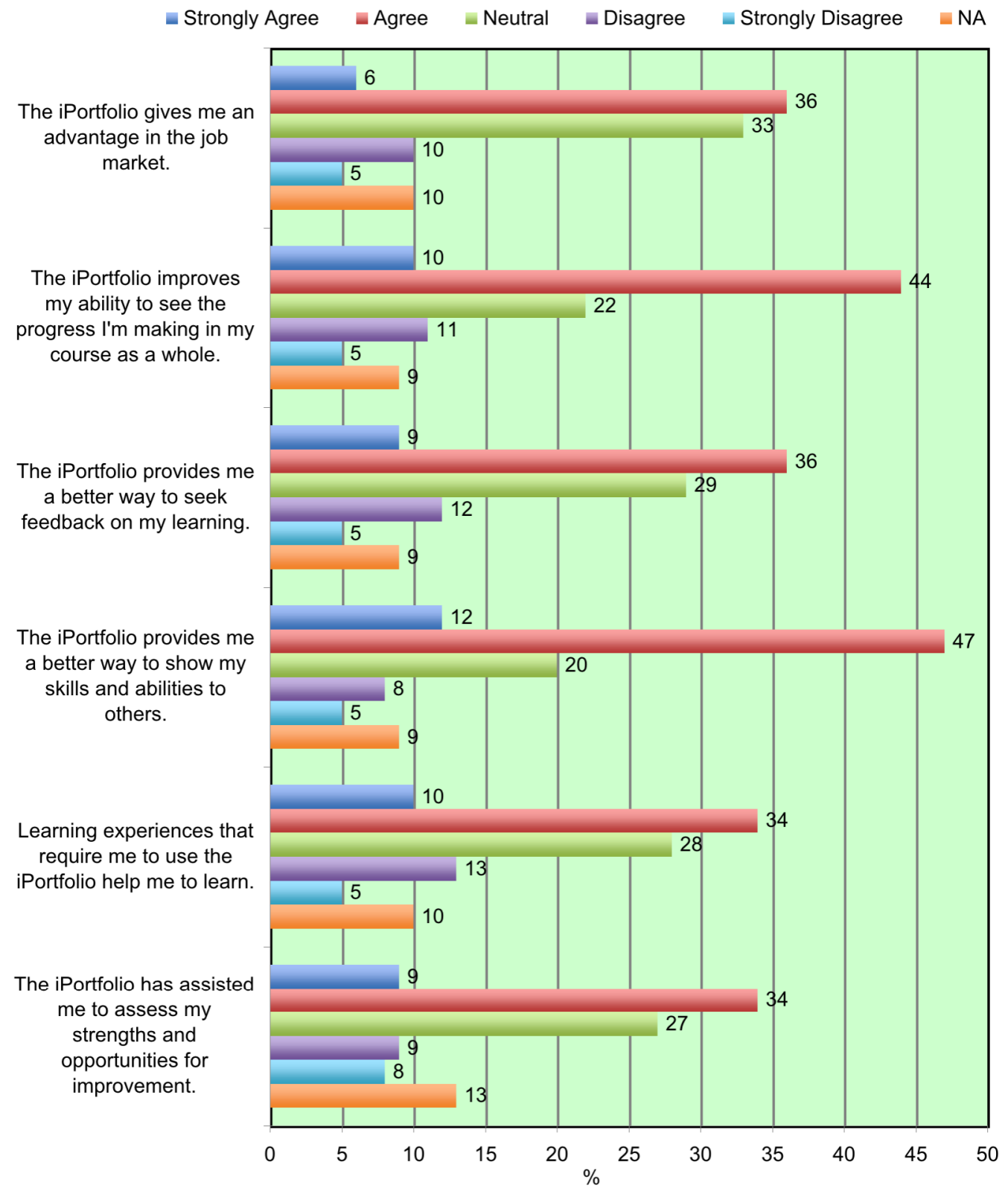

Figure 5: Views regarding iPortfolio utility by those with active accounts 
When asked their level of agreement with the statement: "I am likely to use the iPortfolio in the future, even when it is not required for my course or unit", approximately one third (33.2\%) agreed, and a further $9.7 \%$ strongly agreed. That is, $42.9 \%$ indicated an intention to use the iPortfolio in the future outside of required coursework. There were $29.6 \%$ who were neutral. An additional $14.8 \%$ disagreed, and 9.5 strongly disagreed. That is, fewer than $25 \%$ of respondents indicated that they would only use the iPortfolio if required to do so.

Students were asked to indicate why they were likely to use the iPortfolio in the future from a set of supplied reasons, selecting all applicable answers. The percentage of students indicating a given response is shown in Table 2, sorted by the number of students selecting each possible response. The table shows that about half $(51 \%)$ indicated that they were likely to use the iPortfolio in the future because it would help with their employability; another $51.8 \%$ indicated that they were likely to use the iPortfolio in the future as a place to collect evidence of their learning and achievements.

Table 2: Percentage of students indicating factors leading to future iPortfolio use

\begin{tabular}{|l|c|}
\hline \multicolumn{1}{|c|}{ I am likely to use the iPortfolio in the future because... } & Overall (\%) \\
\hline it will help with my employability & 52.0 \\
\hline I can use it to collect evidence of my learning and achievements & 51.8 \\
\hline I can keep it after I graduates & 46.3 \\
\hline it is a course or unit requirement & 41.8 \\
\hline it is a forum for connecting with potential employers & 35.3 \\
\hline others can offer me feedback on my work & 28.0 \\
\hline I can use it to collaborate with others & 26.3 \\
\hline
\end{tabular}

Factors motivating future iPortfolio use were echoed in open-ended comments. Key factors included use of the iPortfolio to enhance employability and as a repository of their learning outcomes and achievements. For example, students gave the following reasons as motivation for potential future use:

Increasing prospective employment opportunities with the ability to comprehensively format my career-related information.

If employers are going to use it as a tool for looking at employability then I will definitely use it - provides more of a personal touch and an excuse to show off showcase material!

I will be able to use it after graduation and for future employment purposes.

It is an easy way to showcase everything that you do to an employer, especially when not everything will fit into a resume or an interview.

It is nice to have an online medium which allows me to showcase and easily share all my achievements.

I think it is more powerful and an effective way of expressing yourself. It's much better than a paper resume.

Students were asked to indicate barriers to future iPortfolio use, selecting all applicable answers from a supplied set. The percentage of students indicating a given response is shown in Table 3. Just over a quarter $(28.6 \%)$ preferred to store personal information on their own computer, and fewer $(18.6 \%)$ indicated that privacy or security concerns were a barrier to future use. About one-fifth $(19.6 \%)$ indicated that they preferred to 
keep a paper-based portfolio, and about a quarter $(24.3 \%)$ indicated they were unlikely to use the iPortfolio because they did not see the benefit. A small minority (6.9\%) indicated lack of the necessary technical skills.

Table 3: Percentage of students indicating barriers to future iPortfolio use

\begin{tabular}{|l|c|}
\hline \multicolumn{1}{|c|}{ I am unlikely to use the iPortfolio in the future because... } & Overall (\%) \\
\hline I prefer to store personal information on my own computer & 28.6 \\
\hline I don't see the benefit & 24.3 \\
\hline I prefer to keep a paper-based portfolio & 19.6 \\
\hline I have concerns about privacy and the security of my data & 18.8 \\
\hline other sites I use (like Facebook or LinkedIn) are enough for me & 16.1 \\
\hline it is too slow & 10.7 \\
\hline it doesn't have features that I need & 10.3 \\
\hline I don't have the necessary technical skills & 6.9 \\
\hline
\end{tabular}

As shown in Figure 6, most students were confident in their use of information technology, with no significant statistical difference between account holders and nonaccount holders. Three-quarters $(75 \%)$ of respondents agreed when asked the question that "I am generally able to help my peers when they ask me technology-related questions" (no statistically significant difference between account-holders and nonaccount holders; Chi-squared=6.169, d.f. $=5, p>0.5$ ). Similarly, the vast majority agreed that they were able to solve technical problems on their computer "when something goes wrong" (73.9\% agreement overall; Chi-squared=7.696, d.f.=5, p>0.05).

Students were even more confident in their use of technology for specific purposes, with no significant statistical difference between the two groups. For example, most students indicated they were confident in their use of social networking sites like Facebook and YouTube (89.9\% agreement overall; Chi-squared=11.018, d.f.=5, p>0.5), and common computer applications like Microsoft Office ( $94 \%$ agreement overall; Chisquared=4.104, d.f. $=5, \mathrm{p}>0.5$ ). They also tended to agree that they had the technical skills required to use email effectively $(93.5 \%$ agreement overall; Chi-squared $=5.863$, d.f. $=5, p>0.05)$, as well as the Internet $(95.4 \%$ agreement overall; Chi-squared $=6.839$, d.f. $=5, p>0.05)$.

Students in both groups were also comfortable communicating in written English $(92.1 \%$ agreement overall; Chi-squared $=3.571$, d.f. $=5, \mathrm{p}>0.05)$ and in spoken English (92.5\% agreement overall; Chi-squared $=5.907$, d.f. $=5, p>0.05)$, and were able to learn new things without formal lessons (86.9\% agreement overall; Chi-squared=7.267, d.f. $=5, p>0.05$ ), with no significant statistical difference between those with iPortfolio accounts and those without.

Open-ended comments expanded on barriers to future iPortfolio use. Responses indicated that most respondents viewed the iPortfolio more as a means of enhancing employment prospects than as a personal space to reflect on their own learning. In this context, many expressed a concern about employer acceptance and "buy-in" of the iPortfolio for recruitment purposes, or questioned the relevance of the iPortfolio to their discipline. For example, students mentioned the following barriers to future iPortfolio use in their open-ended comments: 


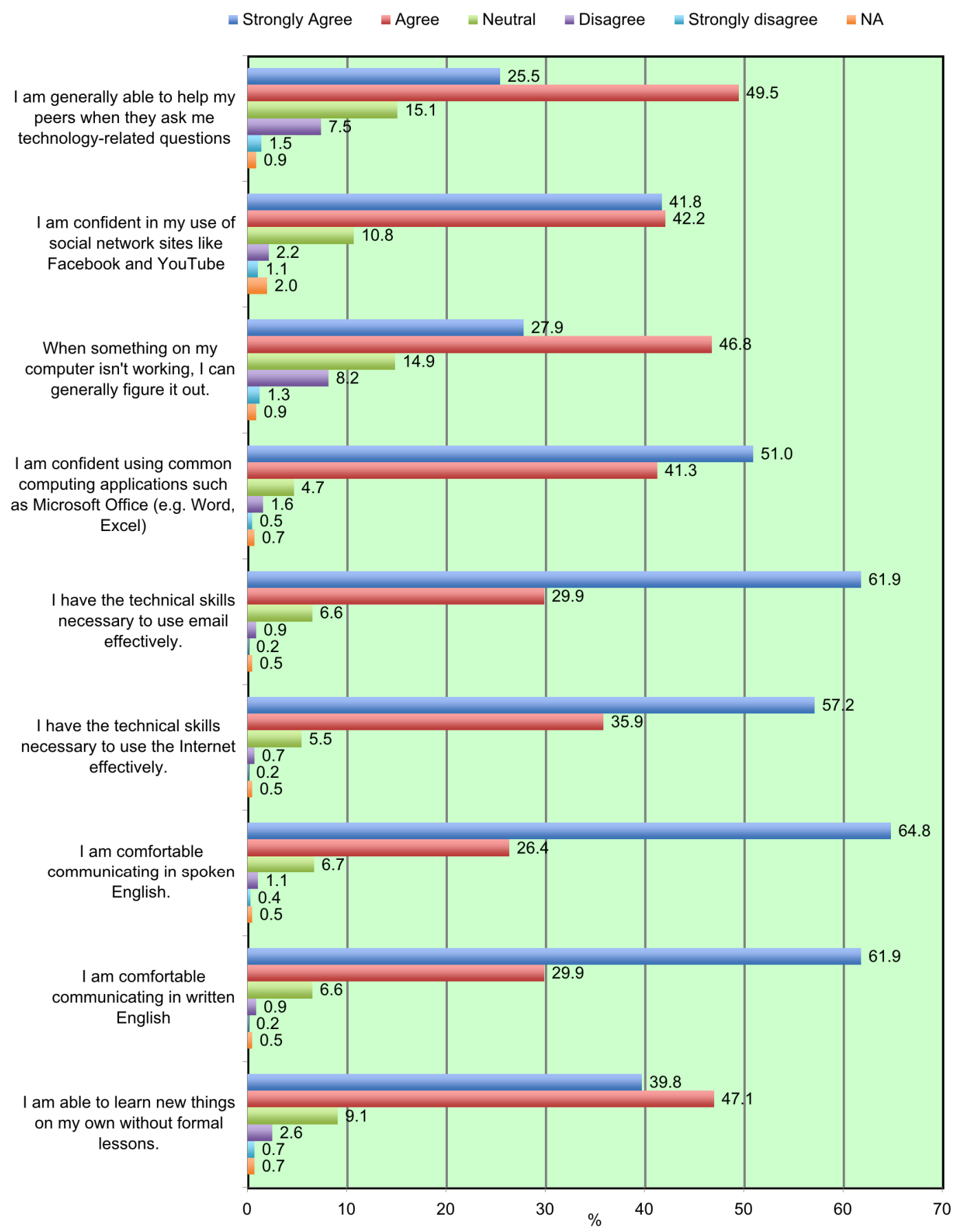

Figure 6: Self-perceptions of abilities related to generic skills. 
May not be appropriate for my profession, I would use it, but I'm not sure prospective employers would go and look at it.

There is no buy-in from potential employers, at least for a Commerce student...

It doesn't send directly to the nurses board like the ANF iFolio does so I'll probably use that one.

External users (that is, those not associated with Curtin) are unlikely to be familiar with i-portfolio and how to use/ access it. I would be more inclined to direct prospective employers / clients to a site they are more familiar with and where they do not require training to use yet another electronic medium.

It would be difficult to explain what 'iportfolio' is to employers that are unaware of it. They do not know what it is, and therefore may not be more useful than a paperback portfolio.

I don't see many companies using this service to interview/gain information about myself in the engineering field.

Others commented that barriers to future iPortfolio use included a preference for other social media sites, or lack of uptake by their peers:

Not that many people I know use it. I'm cool with facebook.

Facebook is more popular today.

Not really applicable for me. Would rather choose other media.

Few of my friends use it or know about it. Even if they did, they would be unlikely to use it.

... Why create a complicated proprietary system to replicate functions readily available elsewhere for minimal or no cost? What's the value proposition?

It was not uncommon for students to describe technical, usability and support issues as barriers to on-going use. For example, students wrote:

Technical issues, e.g. server issues or uptime. Incompatibility issues with chrome.

Often I find my layout has moved around on its own when I log back into it.

Wording/instructions on how to enter data doesn't appear clear enough as I haven't managed to even complete (student or staff or student and staff) section!

To a lesser extent, barriers to future use described by students included the time involved and privacy concerns:

It's just another application to check and update. It's bad enough having another email box at Curtin to check. I already have work and home email addresses, mobile phone etc. I see no point or value in social networking sites, so maybe this is the problem!!

Lack of time to reflect and sort things out.

I like keeping things on my own computer and secure.

I wouldn't like to put too much personal information on there due to privacy issues (as with facebook) 
... I felt it was one other thing $\mathrm{u}$ had to check (email, facebook and oasis are enough for me). It was annoying to invite others for feedback (had to tick both 'view' and 'comment') and cos I wasn't too sure how to use it, I had some privacy concerns- could everyone see my input? I had a video tutorial of me explaining to a patient how to use a vaginal cream! I don't want people seeing that please...

Of those with active accounts $77.5 \%$ reported using their iPortfolio to fulfil unit requirements to some extent, with $62.1 \%$ reporting that they had used it in relation to fieldwork, project work or a site visit directly related to a course or unit. In comparison, $33.8 \%$ reported using their iPortfolio to some extent for purposes not directly related to a unit or course, such as to document professional outcomes arising from club or community group activities. That is, $61.2 \%$ did not use their iPortfolio to document extra-curricular activities. Just over half reported using their iPortfolio to plan their professional development and career direction. These results are expanded in Figure 7.

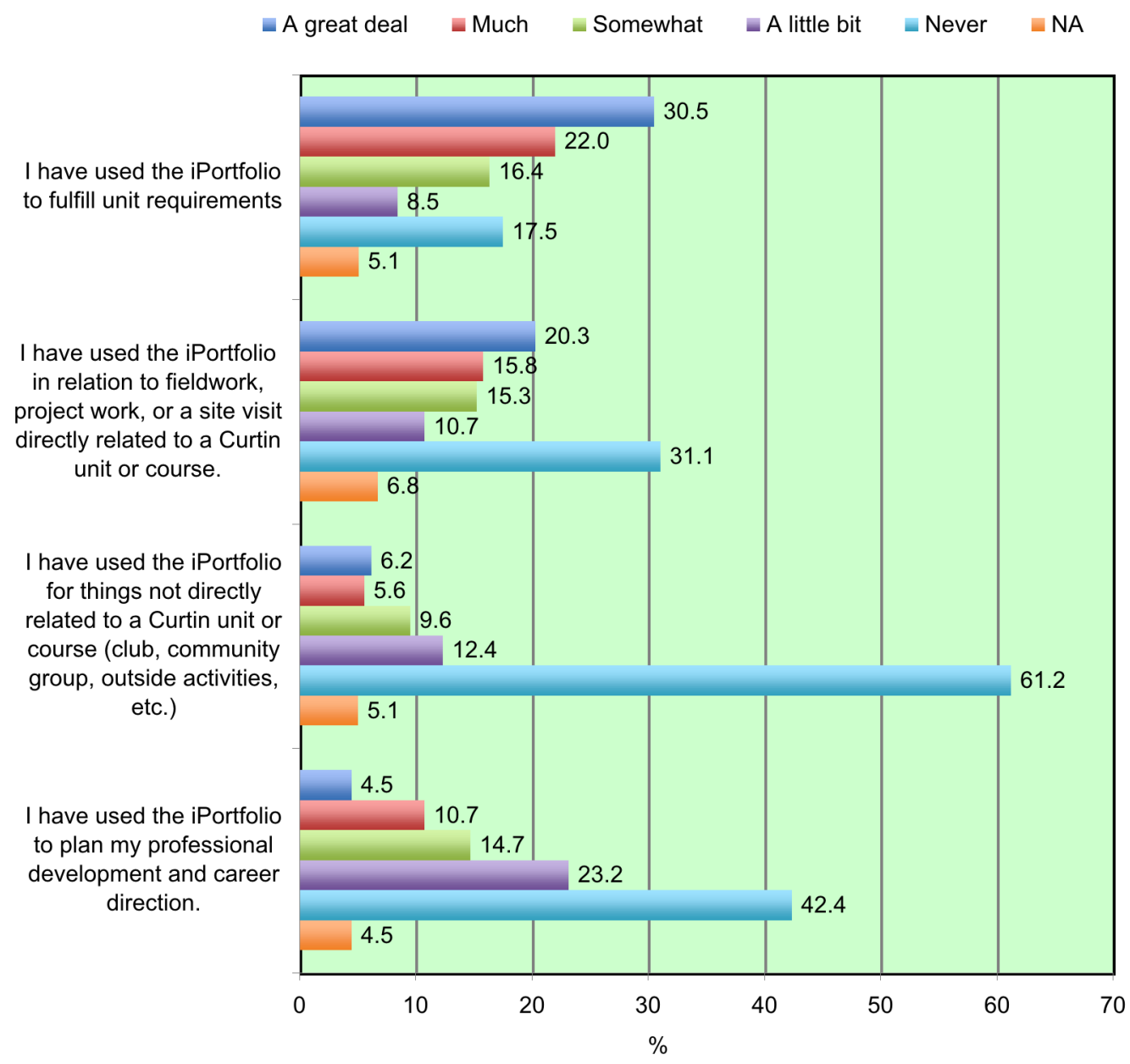

Figure 7: Self-reported iPortfolio use by those with active accounts. 
The tabs modified by students with active accounts are shown in Table 4 . Most students modified the profile entry in the About Me tab. Specifically, $100 \%$ of students with active accounts from Business $(\mathrm{N}=42)$, Health Sciences $(\mathrm{N}=92)$ and Humanities $(\mathrm{N}=9)$, and $97.4 \%(\mathrm{~N}=37)$ of students from Science and Engineering had modified their About Me tab. A total of $48.6 \%(\mathrm{~N}=88)$ had modified their About Me tab only, and had not modified entries under other tabs.

Table 4: iPortfolio tabs used by faculty

\begin{tabular}{|l|c|c|c|c|c|}
\hline \multicolumn{1}{|c|}{ Activity } & $\begin{array}{c}\text { Business } \\
(\mathrm{N}=42)\end{array}$ & $\begin{array}{c}\text { Health } \\
\text { Sciences } \\
(\mathrm{N}=92)\end{array}$ & $\begin{array}{c}\text { Humanities } \\
(\mathrm{N}=9)\end{array}$ & $\begin{array}{c}\text { Science and } \\
\text { Engineering } \\
(\mathrm{N}=37)\end{array}$ & $\begin{array}{c}\text { Overall } \\
(\mathrm{N}=181)\end{array}$ \\
\hline About Me & $100 \%(\mathrm{~N}=42)$ & $100 \%(\mathrm{~N}=92)$ & $100 \%(\mathrm{~N}=9)$ & $97.4 \%(\mathrm{~N}=37)$ & $99.4 \%(\mathrm{~N}=180)$ \\
\hline My Ratings & $42.9 \%(\mathrm{~N}=18)$ & $31.5 \%(\mathrm{~N}=29)$ & $11.1 \%(\mathrm{~N}=1)$ & $7.9 \%(\mathrm{~N}=3)$ & $28.2 \%(\mathrm{~N}=51)$ \\
\hline My Course & $23.8 \%(\mathrm{~N}=10)$ & $32.6 \%(\mathrm{~N}=30)$ & $11.1 \%(\mathrm{~N}=1)$ & $21.1 \%(\mathrm{~N}=8)$ & $27.1 \%(\mathrm{~N}=49)$ \\
\hline My Employment & $21.4 \%(\mathrm{~N}=9)$ & $39.1 \%(\mathrm{~N}=36)$ & $22.2 \%(\mathrm{~N}=2)$ & $15.8 \%(\mathrm{~N}=6)$ & $29.3 \%(\mathrm{~N}=53)$ \\
\hline My Journals & $33.3 \%(\mathrm{~N}=14)$ & $22.8 \%(\mathrm{~N}=21)$ & $0 \%(\mathrm{~N}=0)$ & $15.8 \%(\mathrm{~N}=6)$ & $22.7 \%(\mathrm{~N}=41)$ \\
\hline My Networks & $0.0 \%(\mathrm{~N}=0)$ & $15.2 \%(\mathrm{~N}=14)$ & $0 \%(\mathrm{~N}=0)$ & $2.6 \%(\mathrm{~N}=1)$ & $8.3 \%(\mathrm{~N}=15)$ \\
\hline My Showcases & $31.0 \%(\mathrm{~N}=13)$ & $29.3 \%(\mathrm{~N}=27)$ & $0 \%(\mathrm{~N}=0)$ & $2.6 \%(\mathrm{~N}=1)$ & $22.7 \%(\mathrm{~N}=41)$ \\
\hline
\end{tabular}

Table 4 shows that students in Health Sciences tended to make broader use of the range of available iPortfolio tabs, with around a third of them using the My Ratings, My Course and My Showcases tabs. Slightly more used the My Employment tab, used to store a resume and evidence with reflections that arose from work placements and employment. This uptake pattern can be attributed to an assessment in a health promotion unit and expectations set by a sample iPortfolio for a student nurse. In the health promotion professional practice unit, students were required to reflect on fieldwork placements, and on prior learning that arose during the whole of their course experience (von Konsky \& Comfort, 2010). For this assessment, students were expected to utilise all iPortfolio tabs. Similarly, nursing students were provided with a sample portfolio that made use of all of the iPortfolio tabs, with the exception of the My Networks tab. They were also provided with a template to guide reflections across multiple units based on the professional competencies for nurses and midwives.

Table 4 shows that students in business courses tended to modify the My Ratings tab more than students enrolled in other courses. In part, this could be attributed to a learning experience in an Accounting unit in which students used the My Ratings tab to self assess attainment of graduates attributes as a formative exercise associated with creating a video resume (von Konsky, Oliver, Nikoletatos, \& Wilkinson, 2010). The goal of the My Ratings self-assessment was to identify special skills and strengths and the message to be communicated, in a video resume worth $15 \%$ of the formal assessment in the unit.

The impact of the video resume assessment in Accounting is also reflected in Table 5, which shows that business students tended to upload more movie artefacts than students enrolled in other courses. It should be noted, however, that asset counts are under reported in those cases where assets have been embedded in an iPortfolio but have been stored externally. This was particularly prevalent in Pharmacy, where many students elected to store movies clips of role-played pharmacist-patient scenarios on external sites like YouTube. Although these YouTube videos were embedded in iPortfolio entries, they were not handled by the iPortfolio Evidence Manager and were therefore not included in the asset count metric. 
Table 5: Average active user asset count

\begin{tabular}{|l|c|c|c|c|c|}
\hline Asset type & Business & $\begin{array}{c}\text { Health } \\
\text { Sciences }\end{array}$ & Humanities & $\begin{array}{c}\text { Science and } \\
\text { Engineering }\end{array}$ & Overall \\
\hline Images & 3.0 & 5.4 & 1.1 & 9.9 & 5.1 \\
\hline Movies & 0.8 & 0.2 & 0.0 & 0.1 & 0.3 \\
\hline Audio & 0.0 & 0.0 & 0.0 & 0.0 & 0.0 \\
\hline Documents & 0.3 & 2.8 & 0.1 & 1.1 & 1.6 \\
\hline PDF & 1.4 & 2.7 & 0.0 & 1.1 & 1.8 \\
\hline PowerPoint & 0.2 & 0.1 & 0.2 & 0.2 & 0.1 \\
\hline Excel & 0.1 & 0.3 & 0.8 & 0.1 & 0.2 \\
\hline Other & 0.0 & 0.0 & 0.0 & 0.0 & 0.0 \\
\hline Total & 5.9 & 11.6 & 2.2 & 12.6 & 9.2 \\
\hline
\end{tabular}

Of the 42 Business students with active iPortfolio accounts, 15 were studying in postgraduate programs that required extra-curricular professional development activities to be logged before graduation. The use of PDF files and other documents in Microsoft formats are common artefacts used to document these activities. However, images were the most common type of asset uploaded across all faculties, but more so in Science and Engineering, where student civil engineers kept reflective journals about site visits, using images to visually supplemented critical reflections of the visit and its relationship to classroom-based learning. Typically, these reflective journals contained image artefacts collected by students while on site visits.

Table 6: Average active user tag frequency

\begin{tabular}{|c|c|c|c|c|c|}
\hline Tag & Business & $\begin{array}{l}\text { Health } \\
\text { Sciences }\end{array}$ & Humanities & \begin{tabular}{l|} 
Science and \\
Engineering
\end{tabular} & Overall \\
\hline $\begin{array}{l}\text { Discipline } \\
\text { knowledge }\end{array}$ & 1.2 & 6.5 & 0.3 & 2.0 & 2.2 \\
\hline Thinking critically & 1.5 & 5.7 & 0.3 & 0.9 & 1.9 \\
\hline Information skills & 1.4 & 5.5 & 0.2 & 1.6 & 2.0 \\
\hline $\begin{array}{l}\text { Communication } \\
\text { skills }\end{array}$ & 1.6 & 6.3 & 0.3 & 0.7 & 2.0 \\
\hline Technology skills & 0.9 & 3.5 & 0.2 & 1.9 & 1.4 \\
\hline Lifelong learning & 0.7 & 4.7 & 0.2 & 0.3 & 1.3 \\
\hline $\begin{array}{l}\text { International } \\
\text { perspective }\end{array}$ & 0.7 & 1.6 & 0.3 & 0.1 & 0.6 \\
\hline $\begin{array}{l}\text { Cultural } \\
\text { understanding }\end{array}$ & 0.6 & 2.0 & 0.3 & 0.0 & 0.6 \\
\hline Professional skills & 1.7 & 6.9 & 0.3 & 0.9 & 2.2 \\
\hline Industry experience & 0.3 & 4.5 & 0.1 & 0.8 & 1.3 \\
\hline Global citizenship & 0.0 & 1.7 & 0.1 & 0.0 & 0.4 \\
\hline $\begin{array}{l}\text { Interdisciplinary } \\
\text { experience }\end{array}$ & 0.1 & 1.7 & 0.2 & 0.0 & 0.4 \\
\hline Custom tags & 1.5 & 5.3 & 0.7 & 6.1 & 3.0 \\
\hline
\end{tabular}


Students in all faculties routinely tagged assets (Table 6). Students in the Faculty of Health Sciences were more likely to tag artefacts than students in other faculties, and they used the Discipline Knowledge and Communication Skills tags more frequently than other tags. Engineers tended to use custom tags more than standard Curtin tags. Of the standard Curtin tags, the most frequently used tags were Discipline Knowledge and Technology Skills. Tags for indigenous, intercultural, international, and interdisciplinary educational choices were used less frequently than other tags.

\section{Discussion}

Research Question 1 set out to identify the factors that influenced iPortfolio uptake and use, and Question 2 sought to identify how students were using it. In both cases, results from the student survey and an analysis of iPortfolio server data have demonstrated that iPortfolio uptake and use was driven largely by assessment requirements. This study has shown that students generally intend to use the iPortfolio in the future, even when not required to do so. However, there was no significant evidence to indicate that students were using the iPortfolio to reflect on skills arising from their extracurricular activities or on their professional development, except when required for assessment purposes.

Research Question 3 sought to ascertain whether self-assessed perceptions of technology competence and prior experience with information technology impacted iPortfolio use. A majority of students participating in the study reported use tools like Facebook, Microsoft Office, and email, on a regular basis. This study found no statistically significant difference with respect to self-perceptions regarding information technology competence and the ability to communicate verbally or in writing, when comparing students with and without iPortfolio accounts. This might indicate that self-perceptions regarding competence with these skills was not a significant factor impacting iPortfolio uptake. On the other hand, students with poor information technology skills were probably unlikely to participate in this online survey.

Rogers' diffusion of innovation theory may explain, in part, why students in this study were not using the iPortfolio outside of their formal coursework. According to Rogers, users are more likely to adopt a new technology if it is better than what it replaces, is compatible with existing values, experiences and needs, and is easy to use (Rogers, 2003). The iPortfolio was not intended to replace existing social and professional networking sites, and only $16.1 \%$ of students reported that they were unlikely to use the iPortfolio because sites like Facebook or LinkedIn were enough for them. Nonetheless, is still worth considering iPortfolio adoption in the context of similar tools with which students are already familiar, based on diffusion of innovation theory. Similarly, it is also worth considering how the iPortfolio aligns with existing values, experiences and needs, and the impact this has on iPortfolio adoption and use outside of the formal curriculum.

The present study and others have shown that a majority of students use Facebook for social networking purposes (Oliver \& Nikoletatos, 2009; Oliver \& Whelan, 2011). To a much lesser extent, some students also used LinkedIn for professional networking purposes. In the present study, $89.7 \%$ of the participating students reported having a Facebook account, whereas only $6.7 \%$ indicated that they used LinkedIn. The low adoption of LinkedIn is consistent with data from the Australian Council for Education 
Research indicating that one third of undergraduates leave university without an up to date resume (Australian Council for Educational Research, 2010). Together, these data suggest that undergraduates do not tend to focus on their professional development, or begin preparing for the transition to employment in their chosen field, until they are nearing graduation. It may be that students who intend to use the iPortfolio in the future (33.2\% strongly agree, $9.7 \%$ agree) do so based on a perception this will give them an advantage in the job market $(52 \%)$. Together, this further suggests that adoption of the iPortfolio for non-coursework related purposes might be strongly linked to the process of resume creation and job-hunting in the minds of many students, which they perceive to be an activity that commences just prior to the time of graduation.

The iPortfolio was not created to replace the online spaces students already use for social networking purposes. Indeed, there is an indication that some students prefer to have separate online spaces for the educational, social and professional communities in which they interact (Hoare, 2007). This preference is not without reason. The popular media has carried stories about the negative consequences that have arisen when compromising images and text are posted on social networking sites, but are accessed by potential employers and those other than the intended audience ( $A B C$ Television, 2008).

In contrast, social networking posts made to sites like Facebook also have the potential to illustrate personal activities which contribute to an individual's skills that are of value to prospective employers. For example, a student focus group held during the $i$ Portfolio pre-pilot phase identified existing artefacts depicting professional skills in the form of movies and images stored on participants' Facebook sites. Examples included movies demonstrating teamwork on the football field, and of interdisciplinary collaboration on a motor sports team. Prior to the focus group, these students had not reflected on what these extracurricular experiences contributed to their employability skills, or connected these experiences to those arising from the formal curriculum. An aggregation of these artefacts from existing sources has the potential to encourage students to do so, provided there is a framework to guide their reflection activity.

As an alternative to the current iPortfolio implementation, one might envision a future e-portfolio that integrates distributed digital artefacts with existing forms of social media using tools that students are already using. Researchers at Stanford University, for example, advocate an e-portfolio environment that aggregates artefacts and reflections stored in the Internet cloud on sites like Facebook, YouTube, Google, and Flickr (Kim, Ng \& Lim, 2010). Such a cloud-based e-portfolio architecture is arguably more scaleable and sustainable than one that is dependent upon fixed local infrastructure.

In the context of Roger's diffusion of innovation theory, such an approach would be consistent with a portfolio holder's existing values, experiences, and needs. This is because such an e-portfolio continues to be based on the tools and online sites that the portfolio holder is already using. Such an e-portfolio does not replace those sites or duplicate their functionality. Instead, a cloud-based e-portfolio serves as a selective aggregator of a user's existing digital resources. More importantly, it provides added value as an online space in which the user is able to reflect on the significance of linked digital media that document whole of life experiences in addition to learning arising from the formal curriculum. 
The current version of the iPortfolio does have an extensible facility in which templates can be added to guide reflection activities. For example, a STAR-L template guides students through a reflection exercise in which they reflect on the Situation, Task, Action, Result, and Lessons learned (Cajander, Daniels, McDermott \& von Konsky, 2011). However, currently these reflective templates in the curriculum are under-utilised. Greater user of this facility is envisioned to assist students in learning to write more reflectively than descriptively.

Given that current iPortfolio is drive by assessment, it is also worth considering how the introduction of an e-portfolio into the formal curriculum can provide an opportunity to move to more authentic forms of assessment that enable students to practise and seek peer feedback on workplace based skills, or to reflect on outcomes arising from fieldwork placements or site visits.

For example, in a Pharmacy unit at Curtin, written essays and formal exams have been replaced with a range of authentic iPortfolio-based assessments. In that unit, students video record role-played pharmacist-patient counselling sessions. Recordings are uploaded to each student's iPortfolio, where they receive peer and lecturer feedback using the iPortfolio's social networking features. In a previous study, $47 \%$ of students in the pharmacy cohort reported that they were initially uncertain or negative about this new form of assessment. After engaging in this and other authentic iPortfolio-based learning experiences, this dropped to only $5 \%$ by the end of the semester (Lee, Kinsella, Oliver, von Konsky \& Parsons, 2010). Anecdotally, this positive outcome has been markedly different than in some other teaching areas where the primary emphasis has been on uploading artefacts. In this instance, the introduction of the iPortfolio provided an opportunity to move toward more authentic forms of assessment, and to do so in an engaging and innovative manner. Moreover, the use of digital media and video provide a means to showcase oral communication and other employability skills that are difficult to convey in paper-based formats.

\section{Conclusions}

A student survey has shown that assessment was the largest factor driving iPortfolio uptake and use. This has generally been corroborated by an analysis of usage patterns and uploaded media formats, given assessment patterns in teaching areas where the $i$ Portfolio is a required component. However, this study has also shown that a significant fraction of students intended to use their iPortfolio outside of formal assessment, although there is little evidence to demonstrate that this has occurred to date. Strategies to encourage students to do so should consider aggregating digital artefacts from the cloud providers and social media sites that students are currently using, and to make more extensive use of templates for guiding reflection activities.

Moreover, the introduction of an e-portfolio also presents an opportunity to consider more authentic forms of assessments that reflect the skills and capabilities required in the workplace. Doing so presents an opportunity for students to demonstrate these skills to potential employers, which many students view as the principal benefit for adopting an e-portfolio. Moreover, students are more likely to use a tool like an eportfolio if they see the benefit in doing so, and if it is compatible with their existing values and practices. 


\section{References}

ABC Television (2008). My Face: Will you end up regretting what you reveal about yourself online? The Hack Half Hour. [viewed 13 May 2011]

http: / / www.abc.net.au/triplej/hackhalfhour/programs/s2359534.htm

Australian Council for Educational Research (2010). Doing more for learning: Enhancing engagement and outcomes: Australasian survey of student engagement. Australian Student Engagement Report. ACER. [verified 1 Jan 2012]

http: / / research.acer.edu.au / cgi / viewcontent.cgi?article=1011\&context=ausse

Business, Industry and Higher Education Collaboration Council (2007). Graduate employability skills. Melbourne: Business, Industry and Higher Education Collaboration Council. http: / / www.dest.gov.au/sectors/higher_education/publications_resources/profiles / graduate_employability_skills.htm

Cajander, A., Daniels, M., McDermott, R. \& von Konsky, B. R. (2011). Assessing professional skills in engineering education. Paper presented at the 13th Australasian Computer Education Conference (ACE 2011), Conferences in Research and Practice in Information Technology (CRPIT), Vol 114. http:/ / crpit.com/confpapers/CRPITV114Daniels.pdf

Caruso, J. B. \& Kvavik, R. B. (2005). ECAR study of students and information technology, 2005: Convenience, connection, control, and learning. EDUCAUSE Center for Applied Research. http: / / www.educause.edu/ers0506

Coates, H. (2005). Leveraging LMSs to enhance campus-based student engagement. EDUCAUSE Quarterly Magazine, 28(1), 66-68. http: / / net.educause.edu/ir/library/pdf/ eqm05110.pdf

Elias, T. (2011). Learning analytics: Definitions, processes and potential. [viewed 11 Dec 2011] http: / / www.learninganalytics.net/LearningAnalyticsDefinitionsProcessesPotential.pdf

Graduate Careers Australia (2008). GCA - University and beyond 2007 report. http: / / www.cdaa.org.au/ content/ gca-university-and-beyond-2007-report

Hallam, G., Harper, W., McAllister, L., Hauville, K. \& Creagh, T. (2010). Australian ePortfolio Project, ePortfolio use by university students in Australia: Informing excellence in policy and practice, Supplementary report: October 2010. Australian Learning and Teaching Council. http: / / www.eportfoliopractice.qut.edu.au/survey/index.jsp

Hallam, G., Harper, W., et al. (2008). ePortfolio use by university students in Australia: Informing excellence in policy and practice. Australian ePortfolio Project. http: / / www.eportfoliopractice.qut.edu.au/information/ report/

Hallam, G. \& McAllister, L. (2007). The journey to work: The impact of the ePortfolio on student learning. In Proceedings ATN Evaluation and Assessment Conference. Brisbane, 29-30 November. [verified 1 Jan 2012; $1.9 \mathrm{MB}$ ]

http: / / www.ltu.qut.edu.au/about/ conferencesa/eac2007 / proceedings_ebook.pdf

Hoare, S. (2007). Students tell universities: Get out of MySpace! The Guardian, 5 November. http: / / www.guardian.co.uk/education/2007/nov/05/link.students

Hrabowski, F. A., Suess, J. \& Fritz, J. (2011). Assessment and analytics in institutional transformation. EDUCAUSE Review, 46(5). http:/ / www.educause.edu/library/ERM1150

Johnson, L., Smith, R., Willis, H., Levine, A. \& Haywood, K. (2011). The 2011 Horizon Report. Austin, Texas: The New Media Consortium. http: / / www.educause.edu/ir/library/pdf/HR2011.pdf 
Kim, P., Ng, C. K. \& Lim, G. (2010). When cloud computing meets with semantic web: A new design for e-portfolio systems in the social media era. British Journal of Educational Technology, 41(6), 1018-1028. http://dx.doi.org/10.1111/j.1467-8535.2010.01055.x

Knight, P. T. \& Yorke, M. (2006). Learning and employability series. Enhancing Student Employability Coordination Team, The Higher Education Academy. http:/ / www.heacademy.ac.uk/resources/detail/employability/employabilityemployability-series

Kvavik, R. B., Caruso, J. B. \& Morgan, G. (2004). ECAR study of students and information technology, 2004: Convenience, connection, and control. EDUCAUSE Center for Applied Research. http:/ / www.educause.edu/ECAR/ECARStudyofStudentsandInformat / 158574

Lai, H.-M. \& Chen, C.-P. (2011). Factors influencing secondary school teachers' adoption of teaching blogs. Computers E Education, 56, 948-960. http: / / dx.doi.org/10.1016/j.compedu.2010.11.010

Lee, K., Kinsella, M., Oliver, B., von Konsky, B. R. \& Parsons, R. (2010). Electronic portfolio use as an assessment medium: Pharmacy students' perceptions and experiences. Paper presented at the Learning Forum London 2010, European Institute for E-Learning (EIfEL), London.

Lopez-Fernandez, O. \& Rodriguez-Illera, J. L. (2009). Investigating university students' adaptation to a digital learner course portfolio. Computers $\mathcal{E}$ Education, 52(3), 608-616. http: / / dx.doi.org/10.1016/j.compedu.2008.11.003

Mathews, J. P., Haughton, N., Pisupati, S., Scaroni, A. W. \& DiBase, D. (2004). For an online course encompassing "traditional campus students": How, where, and when students work and engage with the course material. Paper presented at the 34th ASEE/IEEE Frontiers in Education Conference. http:/ / dx.doi.org/ 10.1109/FIE.2004.1408567

Mazzolini, M. \& Maddison, S. (2003). Sage, guide or ghost? The effect of instructor intervention on student participation in online discussion forums. Computers $\mathcal{E}$ Education, 40(3), 237-253. http: / / dx.doi.org/10.1016/S0360-1315(02)00129-X

Oliver, B. \& Nikoletatos, P. (2009). Building engaging physical and virtual learning spaces: A case study of a collaborative approach. In Same places, different spaces. Proceedings ascilite Auckland 2009. http: / / www.ascilite.org.au / conferences/ auckland09/ procs/oliver.pdf

Oliver, B., von Konsky, B. R., Jones, S., Ferns, S. \& Tucker, B. (2009). Curtin's iPortfolio: Facilitating student achievement of graduate attributes within and beyond the formal curriculum. Learning Communities: International Journal of Learning in Social Contexts, Issue 2: e-Portfolio edition, 4-15.

http: / / www.cdu.edu.au/centres/ spill / / journal/IJLSC_Dec_2009_eportfolio.pdf

Oliver, B. \& Whelan, B. (2011). Designing an e-portfolio for assurance of learning focusing on adoptability and learning analytics. Australasian Journal of Educational Technology, 27(6), 10261041. http: / / www.ascilite.org.au/ajet/ajet27/oliver.html

Rogers, E. M. (2003). Diffusion of innovations (Fifth ed.). New York: Free Press.

Rosenbloom, S. (2007). On Facebook, scholars link up with data. The New York Times, 17 December 2007.

http: / / www.nytimes.com/2007/12/17/ style/17facebook.html?pagewanted=all

Salaway, G. \& Caruso, J. B. (2007). The ECAR Study of Undergraduate Students and Information Technology, 2007. EDUCAUSE Center for Applied Research.

http: / / www.educause.edu / ECAR/TheECARStudyofUndergraduateStu / 161967 
Shroff, R. H., Deneen, C. D. \& Ng, E. M. W. (2011). Analysis of the technology acceptance model in examining students' behavioural intention to use an e-portfolio system. Australasian Journal of Educational Technology, 27(4), 600-618. http: / / www.ascilite.org.au/ajet/ajet27/shroff.html

Sutherland, S. \& Powell, A. (2007). CETIS SIG mailing list discussions.

Swan, G. (2009). Examining barriers in faculty adoption of an e-portfolio system. Australasian Journal of Educational Technology, 25(5), 627-644. http:/ / www.ascilite.org.au/ajet/ajet25/swan.html

Tzeng, J.-Y. (2011). Perceived values and prospective users' acceptance of prospective technology: The case of a career eportfolio system. Computers $\mathcal{E}$ Education, 56(1), 157-165. http: / / dx.doi.org/10.1016/j.compedu.2010.08.010

von Konsky, B. R. \& Comfort, J. (2010). The iPortfolio: A tool for work integrated learning for health promotion students. Paper presented at the 2010 ePortfolios Australian Conference.

von Konsky, B. R., Ivins, J. \& Gribble, S. J. (2009). Lecture attendance and web based lecture technologies: A comparison of student perceptions and usage patterns. Australasian Journal of Educational Technology, 25(4), 581-595.

http: / / www.ascilite.org.au/ajet/ajet25/vonkonsky.html

von Konsky, B. R., Oliver, B. \& Ramdin, A. (2009). The iPortfolio: Capture, reflect, share. In Educause Australasia 2009: Innovate, collaborate, sustain. Perth, Western Australia. http: / / www.caudit.edu.au/educauseaustralasia09/assets / papers/tuesday/Brian-vonKonsky.pdf

Authors: Dr Brian R von Konsky, Senior Online Education Developer, Curtin Business School, Curtin University, GPO Box U1987, Perth WA 6845, Australia.

Email: B.vonKonsky@curtin.edu.au Web: http:/ / www.business.curtin.edu.au/

index.cfm/business / staff-directory?profile=Brian-von-Konsky

Professor Beverley Oliver, Pro Vice-Chancellor (Learning Futures), DVC and VP (Academic)'s Office, Deakin University (previously Director, Office of Assessment, Teaching and Learning, Curtin University).Email: B.Oliver@deakin.edu.au

Please cite as: von Konsky, B. R. \& Oliver, B. (2012). The iPortfolio: Measuring uptake and effective use of an institutional electronic portfolio in higher education.

Australasian Journal of Educational Technology, 28(1), 67-90.

http:/ / www.ascilite.org.au/ajet/ajet28/vonkonsky.html 